\title{
AGUAS DISPUTADAS. TRANSFORMACIONES DEL INTERES PÚBLICO (Y PRIVADO) EN EL USO DEL AGUA PÚBLICA ${ }^{1}$
}

\author{
ÁGUAS DISPUTADAS. TRANSFORMAÇÕES DO INTERESSE PÚBLICO (E PRIVADO) \\ NO USO DA ÁGUA PÚBLICA
}

\section{DISPUTED WATER. TRANSFOMATIONS TO PUBLIC (AND PRIVATE) INTERESTS IN THE USE OF PUBLIC WATER}

\section{LES EAUX EN DISPUTE. TRANSFORMATIONS DE L'INTÉRÊT PUBLIC (ET PRIVÉ) AUTOUR DES USAGES DE L’EAU PUBLIQUE}

DOI: $10.5533 / 1984-2503-20135101$

Liber Martin ${ }^{2}$

\section{RESUMEN}

El artículo comienza demostrando la estructura dialéctica que articula la regulación de los derechos de uso especial o privativo de las aguas públicas en Argentina. Luego de constatar la centralidad que el concepto de interés público tiene en la vida de los derechos de aguas (otorgamiento, modificación y extinción), se indaga crítica e históricamente en su funcionalidad y utilización, para concluir propiciando una reducción del margen de

\footnotetext{
${ }^{1}$ Este artículo forma parte de los resultados de la investigación llevada a cabo con motivo de la realización de un proyecto de investigación posdoctoral desarrollado con beca del CONICET (Consejo Nacional de Investigaciones Científicas y Técnicas) en el marco de un proyecto de investigación financiado por la Universidad Nacional de Cuyo (2009-2011), Mendoza, Argentina. E-mail: libermartin@hotmail.com

${ }^{2}$ Abogado por la Universidad Nacional de Cuyo y Doctor en Derecho por la Universidad de Zaragoza, Investigador del CONICET y Profesor de Derecho Administrativo, Ambiental y de Aguas de la Universidad Nacional de Cuyo.
} 
discrecionalidad estatal en su determinación con fundamento en la transformación de elementos sustanciales (dimensión ambiental y social) y procedimentales (incremento de información, participación, planificación, igualdad, libre concurrencia y control judicial) acaecida luego de su sistematización en la década del 40.

Palabras clave: derechos de agua, interés público, uso del agua, ambiente, dominio público.

\section{RESUMO}

O artigo começa demonstrando a estrutura dialética que articula a regulação dos direitos de uso especial ou privativo das águas públicas na Argentina. Após constatar a centralidade que o conceito de interesse público tem na vida dos direitos de águas (outorga, modificação e extinção), indaga-se crítica e historicamente acerca da sua funcionalidade e utilização, para concluir propiciando uma redução da margem de discricionariedade estatal em sua determinação com fundamento na transformação de elementos substanciais (dimensão ambiental e social) y procedimentais (incremento de informação, participação, planificação, igualdade, livre concorrência e controle judicial) ocorrida após sua sistematização na década de 1940.

Palavras-chave: direitos de água, interesse público, uso da água, ambiente, domínio público.

\section{ABSTRACT}

This article begins by outlining the dialectic structure in the regulation of rights to special or private use of public water in Argentina. After examining the centrality that the concept of public interest assumes in terms of water rights (granting, modification and termination), a critical and historical analysis is developed on its functionality and use, to conclude by favouring a reduction in the exercise of discretion by the state in its determination based on the transformation of elements which are both substantial (socially and environmentally) and procedural (increase in information, participation, planning, equality, free competition and judicial control) occurring after systemisation in the 1940s.

Key words: water rights, public interest, water use, environment, public water supply. 


\section{RÉSUMÉ}

Le présent article commence par l'analyse la structure dialectique qui articule la régulation des droits d'usage spéciaux ou privés des eaux publiques argentines. Après avoir constaté la centralité qu'occupe le concept d'intérêt public dans le droit des eaux (concession, modification et extinction), l'on analysera de manière critique et historique la fonctionnalité et l'usage des eaux. L'on en conclura une réduction du pouvoir discrétionnaire de l'État quant à ces usages sur la base de la transformation d'éléments substantiels (dimension environnementale et sociale) et procéduraux (amélioration de l'accès à l'information, participation, planification, égalité, libre concurrence et contrôle judiciaire) ayant eu lieu dans les années 1940.

Mots-clés: droit des eaux, intérêt public, usage des eaux, environnement, domaine public.

\section{Introducción}

Argentina, siguiendo la tendencia mundial, ha incluido la mayoría de sus aguas en el dominio público, relegando las de carácter privado a una categoría indudablemente residual. Aunque no con carácter absoluto, consolidado el principio de publicidad de las aguas (art. 2340 Código Civil argentino, en adelante CC) y el principio de uso racional y sustentable de todos los recursos naturales (art. 41 Constitución Nacional, en adelante $\mathrm{CN}$ ), el problema central del derecho de aguas se desplaza de la propiedad o titularidad hacia la definición del nuevo estatuto de su utilización y el rol mediador que el Estado, como titular del dominio y definidor del interés público implicado en su utilización, adquiere en el conflicto por el acceso al recurso.

Sobre los bienes públicos el derecho ha reconocido tradicionalmente dos formas de utilizaciones: la común y la especial ${ }^{3}$. Uso común es aquél al que los bienes públicos

\footnotetext{
${ }^{3}$ Como se trata de una clasificación aceptada y tratada por la mayoría de los autores de derecho administrativo, teniendo en cuenta los fines del trabajo, nos limitaremos a la cita de dos obras de uno de los autores más representativo del derecho argentino de aguas.
} 
están teóricamente afectados por principio, pueden realizarlos todos los hombres por su sola condición de tales y sin más requisito que la observancia de las disposiciones reglamentarias de carácter general dictadas por la autoridad, como beber, bañarse, lavar ropa, abrevar ganado, etc. siendo generalmente, más no necesariamente gratuito ${ }^{4}$.

El uso especial, privativo, exclusivo o diferencial reviste carácter excepcional y en cambio, es aquel que sólo pueden realizar aquellas personas que se encuentren en las condiciones que al efecto exige la ley, referidas normalmente en la obtención de un título administrativo habilitante (concesión o permiso) ${ }^{5}$. El objeto no es ya satisfacer necesidades físicas indispensables para la vida, sino aumentar la esfera de acción y el poderío económico del hombre e incluyen utilizaciones tales como abastecimiento poblacional, irrigación, industrial, hidroelectricidad, minera, pecuaria, entre otras, resultando a diferencia del anterior generalmente oneroso ${ }^{6}$.

Los bienes públicos, además de ser inalienables, inembargables e imprescriptibles se reputan por principio librados al uso común y sólo por excepción al uso especial o privativo, pero tal formulación de principio en materia de aguas, ha quedado sin embargo, reservada en gran medida a un mero plano teórico ${ }^{7}$. Aunque los usos comunes del agua subsisten, incluso vinculados a institutos como el derecho al agua que los dotan de una

\footnotetext{
${ }^{4}$ Marienhoff, M. (1996). Régimen y legislación de las aguas públicas y privadas, 3. ed., Buenos Aires, Abeledo Perrot, p. 543 y ss.; Marienhoff, M. (1960). Tratado del Dominio Público, Buenos Aires, TEA, p. 291. ${ }^{5}$ Marienhoff, M. (1996). Op. Cit., p. 562.

${ }^{6}$ Ibidem, p. 562; Marienhoff, M. (1960). Op. Cit., p. 291.

${ }^{7}$ Ello al menos por dos razones. La primera es que, en la actualidad en el plano fáctico -no exclusivamente teórico -, los usos comunes en relación a los especiales presentan una muy escasa relevancia cuantitativa mayor aún que la que presentaron antiguamente-. Ello porque, como muestran los textos decimonónicos, fueron concebidos para satisfacer necesidades domésticas en el marco de una economía de subsistencia cuyo ejercicio resulta cada vez más difícil imaginar en el contexto actual donde la escasez, la intensiva, múltiple y sucesiva utilización de las aguas y la contaminación, hacen prácticamente imposible el ejercicio de aquellos usos comunes vinculados a las necesidades domésticas que deben ser satisfechas cada vez más en contextos decididamente urbanos -intermediados por usos especiales- dada la ineludible realidad que representa el dato fáctico de la tendencia mundial al incremento de este tipo de población. Para el año 2025, se prevé el $95.5 \%$ de la población argentina será urbana. Una evolución gradual puede observarse en América Latina, mientras en 1970 el $56.5 \%$ de la población era considerada rural, las proyecciones indican que para el 2025 el $82.8 \%$ de la población va a satisfacer sus necesidades en núcleos urbanos, Boletín Demográfico n. 76. América Latina: Proyecciones de Población Urbana y Rural. 1970-2025, CEPAL, Naciones Unidas, 2005, p. 26 y ss. La segunda, es que en todo caso y en relación con lo anterior, los usos comunes parecen haber variado además de su importancia, sustancialmente su contenido. Sin perjuicio de que se mantengan en muchos sitios los usos comunes "clásicos" o domésticos vinculados a las necesidades de subsistencia, han adquirido una importancia relevante en la actualidad aquellos usos comunes más vinculados al concepto de "calidad de vida", como los denominados usos recreativos (pesca, navegación, esparcimiento, etc.), entre los cuales adquieren a su vez cada vez más relevancia -para los que los consideran tales-, los ecológicos o ambientales. Estas transformaciones (variación cuantitativa y sustancial) permiten constatar que el gran problema del agua se sitúa cada vez más en el campo de su uso especial y no en el común. Así, el teórico principio de uso común de las aguas públicas no sólo se transforma en mito por irreal o imposible, sino que además se configura la paradoja de quedar sujeta en gran medida a un uso privativo conferido por el mismo Estado en las condiciones antes indicadas.
} 
potencialidad muy superior ${ }^{8}$, la muy escasa relevancia que, en términos cuantitativos y cualitativos presentan respecto de la que revisten los especiales hace que nos centremos en el análisis de los derechos que, al amparo de la garantía de la propiedad privada (art. $17 \mathrm{CN}$ ), nacen en virtud de este último tipo de usos.

La disputa principal, por tanto, no es por la propiedad sino por el uso de aguas calificadas formalmente como públicas, pero que a través de una compleja articulación de principios, excepciones que devienen principio, instrumentos y dispositivos legales terminan siendo legalmente utilizadas en exclusivo interés privado.

La dialéctica como recurso lógico o metodológico para explicar el comportamiento de los derechos de aguas constituye un enfoque posible, diverso del dogmático utilizado por la doctrina sistematizadora que sostuvo el carácter esencial, natural o inmutable de sus principios rectores ${ }^{9}$. Esta matriz dialéctica se asienta sobre un concepto clave y central del derecho administrativo que constituye a su vez, el presupuesto esencial de toda utilización especial del dominio público: interés público (y privado $)^{10}$.

El trabajo constata la centralidad que el concepto de interés público tiene en la legislación y el derecho de aguas y la ambigüedad e imprecisión con que es utilizado por parte de la doctrina. Luego indaga en la naturaleza dialéctica de la relación que presenta con el interés privado en general, para centrarse en el análisis de las transformaciones de que esta articulación ha sido objeto desde el contexto decimonónico. Finalmente, se ponen de relieve los elementos de tipo subjetivo, sustancial (reforma constitucional) y procedimental (incremento de información, participación, planificación, igualdad, libre concurrencia y control judicial) que pueden contribuir a la reducción del margen de

\footnotetext{
${ }^{8}$ Ampliar en Martín, Liber et al. (2010). El derecho humano al agua. Particularidades de su reconocimiento, evolución y ejercicio, 2. ed. actual., Buenos Aires: Abeledo Perrot.

${ }^{9}$ Marienhoff, M. (1996). Op. Cit., p. 23/24.

${ }^{10} \mathrm{Tal}$ aptitud proviene de que tales principios, al igual que gran parte del derecho moderno y sus categorías (público y privado, derecho público y derecho privado), forman parte de una relación conceptual difícil de definir con prescindencia de su opuesto, fuera de la lógica de su aparente contradicción. Vid. Parejo Alfonso, Luciano (2005). "Interés público como criterio de control de la actividad administrativa". In AAVV, Constitución, Estado de las Autonomías y Justicia Constitucional, (Homenaje a Grumersindo Trujillo), Valencia: Tirant lo Blanch. Prerrogativa y garantía, poder y libertad, constituyen términos eminentemente dialécticos a partir de los cuales se ha definido también al derecho administrativo. Cfr. Comadira, Julio R. (2004). "El Derecho Administrativo como régimen exorbitante en el servicio público". In Servicio Público, Policía y Fomento, Jornadas de la Universidad Austral, RAP, p. 18. Resulta insoslayable el andamiaje teórico utilizado para fundar una perspectiva de este tipo en De Cabo de la Vega, A. (1997). Lo público como supuesto constitucional, México DF: UNAM.
} 
discrecionalidad estatal en su determinación con relación al supuesto concreto del uso especial del agua pública ${ }^{11}$.

\section{Interés público (y privado) en el uso de las aguas públicas}

Una primera y obligada precisión metodológica y terminológica lleva a descartar de plano una completa consideración del "interés público" como instituto y concepto cuanto a señalar que, en el marco de la doctrina iusadministrativista moderna, la clasificación de intereses en públicos y privados ha sido amplia y comúnmente aceptada ${ }^{12}$.

La recurrencia con que la legislación argentina de aguas, pero en mayor medida la doctrina y la jurisprudencia apelan al concepto de "interés público" o "interés general" en contextos diversos, a la vez que parece tornar innecesaria su cita, revela la naturaleza multívoca, polisémica e ideológica que en ocasiones presenta ${ }^{13}$.

Baste mencionar como ejemplo la centralidad que en la actualidad adquiere este concepto en relación a la conformación del dominio público hidráulico en la legislación argentina al incluir en él "...toda otra agua que tenga o adquiera la aptitud de satisfacer usos de interés general..." (art. 2340 inc. $3^{\circ} \mathrm{CC}$ ).

Ahora bien, el hecho que el concepto de interés público sea una de las nociones centrales y más discutidas del derecho administrativo la constituye a la vez como un presupuesto cuya referencia, aunque sea parcial, resulta insoslayable en tanto aparece,

\footnotetext{
${ }^{11}$ Frente a la postura mayoritaria que constata la imposibilidad de precisar su contenido, con ocasión de la cual Nieto se pronunciara señalando que ni la ciencia ni la práctica están en condiciones de determinar lo que sean lo intereses generales y cual sea su papel para el Estado, Parejo Alfonso ha postulado el carácter definible o en todo caso constatable del interés público (sic), Parejo Alfonso, I. (2005). Op. Cit., p. 267/269; también en Parejo Alfonso, Luciano (2007). "Estudio preliminar". In Marin Hernandez, Hugo A. (2007), Discrecionalidad Administrativa, Bogotá: Universidad Externado de Colombia, p. 27 y ss.

${ }^{12} \mathrm{Y}$ ello porque el interés constituye un concepto central del derecho moderno y ha sido adjetivado de las más diversas formas en las distintas ramas del derecho (interés simple, legítimo, jurídicamente protegido, privado, público, colectivo, difuso, etc.), acarreando consigo trascendentes consecuencias jurídicas que denotan una complejidad que resulta aquí de imposible tratamiento.

${ }^{13}$ El carácter indeterminado del concepto de interés público o interés general, y las consecuencias que de ello se derivan ha sido objeto de reflexión constante por parte de la literatura administrativista. En la doctrina española entre muchos autores que se han ocupado del tema en general con especial interés, Sainz Moreno, F. (1976). Conceptos jurídicos, interpretación y discrecionalidad administrativa, Madrid: Civitas. En particular, han participado de la polémica Beltrán de Felipe, M. (1995). Discrecionalidad administrativa y Constitución, Madrid: Tecnos; García de Enterría, E. (1996). Democracia, jueces y control de la Administración, 2. ed., Madrid: Civitas; Nieto, A. (1997). "La Administración sirve con objetividad a los intereses generales". In Estudios sobre la Constitución Española (Homenaje a Eduardo García de Enterría), Madrid, Civitas, v. III, p. 2185 y ss; Parejo Alfonso, L. (2005). Op. Cit., p. 251-269. Trabajos a cuyas abundantes citas bibliográficas, en honor a la brevedad, cabe remitirse.
} 
en lo que a este trabajo concierne, como fundamento y presupuesto genérico universal de cualquier utilización privativa de bienes públicos y desde luego de las aguas.

En efecto, la doctrina ha reconocido que el concepto de interés público constituye la base de sustentación del derecho administrativo erigiéndose a la vez como fundamento y límite de toda la actividad administrativa ${ }^{14}$. $Y$ esto es posible explicarlo desde un contexto más amplio, puesto que el interés público se ha constituido -en última instancianada más ni nada menos que en la justificación de la actuación legal y administrativa de todo el Estado liberal de derecho, frente a sí mismo y frente a terceros ${ }^{15}$. De allí, el uso ideológico que al mismo en ocasiones se atribuye.

Pero volviendo al supuesto que nos ocupa, el uso y goce de los bienes públicos es teóricamente, por principio, común a todas las personas y sólo excepcionalmente puede ser especial o privativo, si se cuenta con el pertinente título administrativo en el caso de las aguas.

Aguas públicas cuya razón de ser en términos generales, e históricos inclusive, no ha sido tanto la propiedad estatal como la de impedir su apropiación privada por parte de particulares para garantizar su disposición general o pública, pero cuyo destino principal a su vez, no puede ser otro que el de su utilización por "el público", sea en forma común, sea en forma privativa.

El uso especial o privativo de aguas públicas involucra así un "interés privado" del particular enderezado a la obtención de un lucro o beneficio privado legítimo que provoca el ensanchamiento de su esfera patrimonial y que no aparece descontextualizada sino vinculada al ejercicio de otros derechos como la libertad de empresa, el derecho al trabajo, etc. a cuya realización el Estado debe también propender (arts. 14/75 inc. 22 CN). Pero implica necesariamente también un "interés público", en el ordenamiento administrativo de esa utilización y en la promoción de una más productiva y eficiente utilización de los recursos hídricos a través de la determinación o indicación de los usos y condiciones que propenda en definitiva a la prosperidad, el desarrollo económico y humano, también querido por la Constitución.

\footnotetext{
${ }^{14}$ Escola, H. J. (1989). El interés público como fundamento del derecho administrativo, Buenos Aires: Depalma; Salomoni, J.L. (2006), Ordenamientos Internacionales y Ordenamientos Administrativos Nacionales. Jerarquia, impacto y derechos humanos, Buenos Aires: Ad Hoc, p. 23; Parejo Alfonso, L. (2005). Op. Cit., p. 263 y ss. Genéricamente planteado el interés público aparece también como presupuesto de cualquier actuación administrativa en tanto su falta o ausencia, desde otra perspectiva, configura desviación de poder.

${ }^{15}$ Habermas, Jürgen (1981). Historia crítica de la opinión pública, Barcelona: G. Galli, p. 18/19.
} 
Esto implica la concurrencia de dos tipos de intereses aparentemente encontrados -del particular y la administración- cuya importancia, equiparable para sus titulares respectivamente desde un paradigma contractual o sinalagmático, no lo es sin embargo, para el ordenamiento administrativo, donde la finalidad pública vinculada al interés general, debe prevalecer por principio sobre el fin privado o particular ${ }^{16}$.

Esta es por otra parte la tesis que se desprende de la jurisprudencia de la CSJN (Corte Suprema de Justicia de la Nación) cuando ha sostenido que: “...su caducidad está sometida al criterio y apreciación de la misma, según se considere que subsisten o no los motivos de utilidad general que fundaron aquéllas, sin que ningún interés de orden privado pueda sobreponerse a las consideraciones y voluntad del concedente" (cons. 5ำ )$^{17}$.

En este contexto, y desde la óptica del ordenamiento administrativo, la justificación de los derechos de utilización especial o privativa de los bienes públicos por particulares y del mecanismo de la concesión, en tanto instrumento que lo hace posible, no descansa tanto entonces en el interés privado patrimonial exclusivo del concesionario, cuanto en la finalidad pública a la que está indisolublemente unida durante toda su duración. Interés público o general cuya determinación ha correspondido tradicionalmente a la administración, que lo ha efectuado en ocasiones y en las diversas fases procedimentales -otorgamiento, modificación, extinción- de manera ciertamente discrecional, arbitraria, negligente, cuando no prebendaria.

El problema teórico que se deriva de considerar que los derechos se fundan en el interés público (y privado) puede consistir en determinar en qué medida ese interés "público" en la utilización privativa del agua representa o refleja los intereses particulares o individuales de cada uno de los ciudadanos, y viceversa, en que medida ese interés "privado" contribuye o implica de manera significativa el logro de los intereses generales ${ }^{18}$.

Pero en el marco de la dialéctica propuesta, más que disputar si el uso especial es efectuado en interés público o privado, es posible postular que ambos se encuentran implicados y que la cuestión a dilucidar es, por tanto, su modo de articulación y la forma de determinación que ambos presentan en un contexto referencial determinado, sin

\footnotetext{
${ }^{16}$ Marienhoff, M. (1960). Op. Cit., p. 346/358 y ss. En igual sentido el CAg. de Salta sienta el principio de que "...Los proyectos de interés general de uso múltiple, técnica, económica y socialmente justificados tienen prioridad sobre los de uso singular o particular" (art. 9 CAg. Salta).

${ }_{17}$ CSJN, in re "SA Puerto de San Nicolás v. Provincia de Buenos Aires", Fallos 141:190 (16/02/1911).

${ }^{18}$ Ver las contradicciones en las que incurren algunos juristas clásicos al intentar justificar esto sin adoptar una mirada más compleja, por todos ver Marienhoff, M. (1960). Op. Cit., p. 358/359.
} 
perjuicio de la dinámica o preeminencia que pueda reconocerse a uno sobre el otro conforme la variación del marco contextual ${ }^{19}$.

En efecto la configuración dialéctica no sólo no es ajena al derecho y los cuerpos

normativos, sino más bien consustancial al mismo. Con claridad Parejo Alfonso refiere:

[...] existe un único orden constitucional, que preside un ordenamiento jurídico articulado sobre la base de la diferenciación de dos mundos en relación dialéctica entre sí (diferenciación paralela a la que se da entre las de las cosas -cosas públicas y cosas privadas- $y$ las de las actividades -actividades privadas $y$ públicas-); los mundos de lo privado (el interés privado) y lo público (el interés general) ${ }^{20}$.

\title{
2. Dialéctica interés público-interés privado
}

\author{
Desde un punto de vista, se ha dicho que:
}

[...] el interés público expresa una superación de los intereses particulares; tal superación significa en principio una negación. El interés público se distingue de los intereses particulares, es de otra naturaleza, expresa el rechazo de la limitación que expresa su particularidad, su emancipación. El interés público no emana de los intereses particulares; les sobrepasa en un doble sentido donde, situado más allá de sus conflictos los desploma y los domina. Entre el interés público y el interés particular se establece entonces una relación de jerarquía. El

\footnotetext{
${ }^{19}$ Un razonamiento distinto que negara la existencia de un término llevaría también, en términos dialécticos, a la desaparición de ambas categorías cuya existencia o definición sólo es posible en relación a la otra. En otras palabras, desde esta perspectiva no parece conveniente definir a los derechos de uso especial -y los principios que informan su régimen jurídico- en términos de interés público o privado, precariedad o seguridad, rigidez o flexibilidad. Desde la perspectiva dialéctica necesariamente implican intereses públicos y privados y resultan por tanto precarios y seguros, rígidos y flexibles al mismo tiempo. La tensión o contradicción es lo que posibilita su existencia. La forma en que tal contradicción se resuelve, la manera en que esos términos se articulan para un momento dado, determina la configuración del principio en un contexto y arroja datos sobre la mayor o menor precariedad que el derecho tiene o el principio denota en relación a otra configuración contextual. Si desaparece todo grado de precariedad, en términos estrictamente dialécticos, desaparece también la posibilidad de seguridad como categoría que se conforma en tensión permanente a partir de su opuesto.

${ }^{20}$ Parejo Alfonso, L. (2005). Op. Cit., 259. El problema se conecta así aunque no se identifica plenamente, con una distinción cuyos limites son aún más difíciles de precisar: derecho público y privado, y más genéricamente con "lo público" y lo privado. Un profundo estudio sobre la complejidad de la cuestión puede verse en, De Cabo de la Vega, A. (1997). Op. Cit.; Sobre la diferenciación derecho público derecho privado, vid. Bullinger, Martin (1976). Derecho público y Derecho privado, Madrid, Instituto de Estudios Administrativos. Traducción A. Esteban Drake. No son pocos los trabajos que, aunque de manera generalmente implícita, adoptan como base esta concreta relación dialéctica. Entre otros, Embid Irujo, A. (1997), "Público y privado en la construcción, explotación y mantenimiento de obras hidráulicas"..., y sus citas; Desde un enfoque más próximo a la economía, AAVV (2005). Lo público y lo privado en la gestión del agua. Experiencias y reflexiones para el siglo XXI, Madrid: Ediciones del oriente y del mediterráneo.
} 
primero se impone al segundo al cual trasciende. El interés público se presenta puro y único, como exterior y diferente de los intereses particulares, impuros y múltiples. Debido a una existencia propia, a una representación autónoma; y es que el interés público puede asegurar su superioridad y su supremacía sobre todos los otros intereses. En este caso no hay entre el interés público y los intereses particulares solución de continuidad; el interés público resulta de una ruptura con los intereses particulares. La ideología del interés general opera una conciliación entre el interés común, inmanente de los intereses particulares y el interés público, trascendente de estos mismos intereses ${ }^{21}$.

Esta concepción abstracta de interés público refleja, en realidad, su posible manipulación o utilización ideológica ${ }^{22}$.

Desde otro punto de vista y en un intento por desmitificar esa concepción, Gordillo advierte sobre:

[...] el error de concebir al interés público o a la necesidad pública como entes abstractos, como una estela de bienestar que se esparce insensiblemente entre el pueblo; como una noción mágica que implica todo lo bueno y mejor y a la cual deben doblegarse las pretensiones jurídicas de los particulares. El interés público sostiene- no es el interés de un conjunto de habitantes tomados como masa; no es un bienestar general, omnipresente, una felicidad imprecisable: es sólo la suma de una mayoría de intereses individuales coincidentes ${ }^{23}$.

Las concepciones expuestas permiten efectuar a priori una serie de constataciones. La primera de ellas es que aparece como una simplificación y por tanto, un error el establecer tanto una identificación como una contraposición de tipo absoluto entre ambos tipos de intereses que resulta en ocasiones maniquea o ideológica. La diferencia y simultánea implicación entre intereses generales y particulares constituye un presupuesto muy difícil de controvertir ${ }^{24}$. Aunque esa aseveración podría, en el extremo de confundirlos totalmente, llevar a alguien a afirmar que la distinción carece de sentido, y

\footnotetext{
${ }^{21}$ Hernández Martínez, Ma. del Pilar (1997). Mecanismos de tutela de los intereses difusos y colectivos, México: Instituto de Investigaciones Jurídicas, UNAM, p. 58/59.

${ }^{22}$ Sobre el uso ideológico del concepto, entre otros, D’Argenio, Inés (2007). "La ideología estatal del interés general en el derecho administrativo". In RDA, Buenos Aires, n. 59; Rangeon, Francois (1986). L'idéologie de l'íntéret general, Paris: Económica; Habermas, J. (1981). Op. Cit.; también, Salomoni, J. L. (2002). "Interés Público y Emergencia". In Revista Actualidad en el Derecho Público, Buenos Aires, n. 18-20.

${ }^{23}$ Gordillo, A. (2004). "Reestructuración del concepto y el régimen jurídico de los servicios públicos", Buenos Aires. In Paginas de Ayer - 10, 29, LL.

${ }^{24}$ Esto parte de la misma concepción unitaria del texto constitucional que resguarda de manera simultánea ambos tipos de intereses. Como afirma Parejo Alfonso: "En el bien entendido de que se trata de una diversidad no conducente necesariamente a una contraposición, pues los dos tipos, <<privado $>>$ y <<público>>, de relación (interesamiento) en función del único orden de bienes y valores son necesarios y complementarios (uno necesita del otro) para la realización de tal orden. No puede olvidarse, en efecto, que el orden político y la paz social cuya efectividad es inherente a la Constitución según su art. 10.1, descansa en la dignidad y libertad de la persona entendida como valor complejo, en el que se funden indisociablemente la individualidad y la socialidad", Parejo Alfonso, L. (2005). Op. Cit., p. 258/259.
} 
a tal postura le asistiría razón en la medida en que la noción se vuelve más abstracta, vacía de contenido, descontextualizada y por ende carente de utilidad.

Y es que no obstante la acertada crítica de que es pasible la mítica -por funcional e indeterminada- concepción del interés público o general, el breve relato efectuado permite intuir que el contenido del interés público parece ser el resultado de un proceso un tanto más complejo que una simple suma aritmética de intereses particulares. Desde esta perspectiva, interés privado e interés público parecen moverse en distintos planos, que no permiten sin embargo descartar a priori vinculaciones entre ellos, y sin que necesariamente por tanto uno implique la negación del otro. Más que una identificación lineal, una contraposición rígida o el resultado de la simple suma de intereses individuales, parece establecerse una relación dialéctica esencialmente dinámica entre interés público e interés privado que, a veces y dependiendo del contexto, puede implicar cierta identidad, negación o llegado el caso, una sumatoria de ellos. Sólo en este sentido entonces parece posible decir que el interés público o general implica una superación de los intereses individuales o particulares.

Superadas ya las concepciones subjetivistas que postulaban la identificación de los intereses públicos con los intereses del Estado ${ }^{25}$, o las que postulan su identificación sin más con intereses sectoriales o corporativos -como la que probablemente ha tenido lugar de manera preeminente por parte de los usuarios con derechos privativos al uso del agua hasta la actualidad- ${ }^{26}$, se ha formulado una concepción sustancialista a partir de la cual se

\footnotetext{
${ }^{25}$ Desde una perspectiva iusfilosófica, la tensión interés particular - interés general es resuelta por Hegel en favor del Estado al punto de prácticamente confundirlos. Así, señala que "...La esencia del nuevo Estado es que lo universal está unido con la completa libertad de la particularidad y con la prosperidad de los individuos, que el interés de la familia y la sociedad civil deben concentrarse, por lo tanto, en el Estado, y que la universalidad del fin no debe progresar sin embargo sin el saber y querer propio de la particularidad, que tiene que conservar su derecho. Lo universal tiene pues que ser activo, pero por otro lado la subjetividad tiene que desarrollarse en forma completa y viviente. Sólo si ambos momentos se afirman en su fuerza, puede considerarse que el Estado está articulado y verdaderamente organizado (...) El interés particular no debe ser dejado de lado ni reprimido, sino que debe ser puesto en concordancia con lo universal, con lo cual se conserva lo universal mismo. El individuo que se subordina a sus deberes encuentra en su cumplimiento como ciudadano la protección de su persona y propiedad, la consideración de su bienestar particular y la satisfacción de su esencia sustancial, la conciencia y orgullo de ser miembro de esa totalidad. En el cumplimiento de los deberes en la forma de prestaciones y servicios para el Estado, tiene el individuo su conservación y su existencia..." Hegel, G.W.F. (1975). Principios de la filosofía del derecho o derecho natural y ciencia política, Bs. As.: Sudamericana, p. 48/49.

${ }^{26}$ En la doctrina española y desde una perspectiva crítica a la participación entendida como participación exclusiva y corporativa de los titulares de derechos de uso especial sobre el agua pública. Garces, Ángel (2005). "El interés general como aspecto esencial del dominio hidráulico". In Revista Aragonesa de Administración Pública, n 27, p. 137 y ss.; Garces, Ángel (2001). "Participación Social y gestión institucional del agua". In Una cita europea con la nueva cultura del agua: La directiva marco: perspectivas en Portugal y España, Zaragoza, p. 463-480; Garces, Ángel (1999). "Aspectos prácticos de la planificación y de gestión institucional del agua. La gestión privada de intereses públicos". In AAVV (1999). El Agua a Debate en la Universidad. Hacia una nueva cultura del agua, Zaragoza.
} 
propone hablar de intereses públicos concretos, de interés público en plural, y de intereses públicos heterogéneos ${ }^{27}$. Con lo cual el problema se traslada en buena medida a los mecanismos y procedimientos para la determinación de ese interés y al valor o la función que a él se reconozca con posterioridad ${ }^{28}$.

Aunque poniendo énfasis en la función de control, Nieto reconoce que: “...los intereses generales son indefinidos (en cuanto que ninguna norma lo hace) e indefinibles objetivamente (en cuanto que no existe criterio alguno para realizar esta operación), con la consecuencia de que su función primordial sigue siendo ideológica, es decir, de cobertura legitimadora de los Poderes públicos para justificar el contenido de sus decisiones e incluso su mera intervención formal en las relaciones sociales"29.

Es que no debe olvidarse que parte de la complejidad del debate en los términos antes expuestos, y de la imposibilidad de su clausura y definición a priori, viene de que los conflictos por la determinación de/los interés/es público/s, aunque fuertemente intermediados por el derecho, el lenguaje y los conceptos jurídicos, no deja de ser a la vez como lo ha sostenido el propio Kelsen un conflicto de eminente corte político ${ }^{30}$. Circunstancia que se conecta, además, con el mayor o menor carácter discrecional de su determinación.

Dando cuenta de ello y de las consideraciones efectuadas en los párrafos precedentes, para el caso específico de las aguas la doctrina española ha advertido cómo debe cuidarse de no identificar los intereses de usuarios y ciudadanos, que resultan en todo caso sectoriales, con el interés público o general sobre el que se viene

\footnotetext{
27 Weber, Max (1969). Economía y sociedad, México: FCE, T. II, p. 498. También refiriendo a la heterogeneidad del los intereses públicos, Giannini, Massimo Severo (1970). Diritto Administrativo, Milano, Giuffrè, v. I, p. 106; Sanchez Moron, M. (1980). La participación del ciudadano en la Administración pública, Madrid: Centro de Estudios Constitucionales, p. 131/132; Cassese, S. (2003). La crisis del Estado, Buenos Aires: Abeledo Perrot, p. 156.

${ }^{28}$ Sanchez Moron descartando los criterios subjetivos y objetivos para definirlos concluía que el problema no estaba en elaborar una definición genérica del interés público, sino en establecer cómo se procedía jurídicamente a su identificación y qué utilización debía darse a los mismos una vez identificados, Cfr. Sanchez Moron, M. (1980). Op. Cit., p. 131/132.

${ }_{29}^{29}$ Nieto, A. (1997). Op. Cit., p. 2251.

30 "...Todo conflicto jurídico es, por cierto, un conflicto de intereses, es decir, un conflicto de poder; toda disputa jurídica es consecuentemente una controversia política, y todo conflicto que sea caracterizado como conflicto político o de intereses o de poder puede ser resuelto como controversia jurídica, Kelsen, Hans (1995). ¿Quién debe ser el defensor de la Constitución?, Madrid: Tecnos, p. 21. Por su parte, el inspirador de la CN argentina "...no nos demos prisa a poner término a un problema tan antiguo y quizás tan eterno como el hombre: la relación de la individualidad con la generalidad. Es el nudo gordiano que mientras los filósofos se ocupan de desatar, los gobiernos lo cortan cuando les conviene. Déseme un límite indestructible entre estos dos términos del problema social, y doy la cuadratura del círculo, el movimiento perpetuo", Alberdi, Juan Bautista (1998), Fragmento Preliminar al estudio del Derecho (1837), Buenos Aires: Ciudad Argentina, p. 80/178.
} 
discurriendo ${ }^{31}$. Ahora bien, ante la evidencia de que tales intereses no resultan puramente "individuales" sino que pueden considerarse sectoriales, parece clara la idea antes referida de que nos encontramos, en realidad, frente a una pluralidad o heterogeneidad de intereses públicos ${ }^{32}$.

En efecto, la creciente participación ciudadana ha comenzado a cuestionar la función del interés general en el uso privativo de las aguas, exigiendo una mayor racionalidad, un mayor estudio y una participación y justificación auténtica de las decisiones que bajo tal velo la administración toma ${ }^{33}$.

Creemos en definitiva, que no tiene demasiado sentido negar la existencia de la distinción entre interés público y privado -con lo cual por otra parte podría estarse negando en el fundamento mismo del derecho administrativo-, cuya relación con referencia al uso especial de bienes públicos puede bien caracterizarse como dialéctica.

La constatación de la centralidad que el concepto de interés público adquiere en el régimen del uso privativo, sugiere sin embargo dejar de lado las definiciones, la

\footnotetext{
${ }^{31}$ Así, se ha advertido sobre el cuidado que debe tenerse de "...no realizar una simplificadora equivalencia entre usuarios=intereses particulares, y por tanto egoístas, y representación ciudadana=defensa de intereses generales y por tanto puros e inmaculados. Puede convenirse inicialmente en que por definición los usuarios (en cuanto titulares de un derecho al uso privativo de las aguas) representan intereses particulares [...] Las representaciones ambientales, de consumidores, de vecinos, empresariales 0 sindicales, pueden representar -y de hecho representan- intereses tan sectoriales como los de los usuarios, y sería falso equiparar la falta de derecho al uso privativo del agua a visión no interesada o no egoísta de tal uso..." Embid Irujo, A. (2008). "Usuarios y ciudadanos: participación e información ...". In Embid Irujo, A. (Dir.) (2008). Ciudadanos y usuarios en la gestión del agua, Aranzadi: Cizur Menor, p. 63.

${ }^{32}$ Críticamente se apunta: "...la gestión del agua ya es en buena medida privada e, incluso, las propias competencias públicas de la gestión (la planificación,... o la atribución de concesiones) se ven influidas por intereses privados, con lo que dichos conjuntos sólo pueden ser disjuntos en el simplismo de ciertas discusiones académicas entre economistas, pero no lo son para los juristas. Pues en el tema del agua $-\mathrm{y}$ en otros muchos - lo público y lo privado, las políticas y los mercados..., tienen que ver con los forcejeos del poder, en los que ciertos intereses privados consiguen imponerse como públicos estableciendo un determinado marco jurídico y los economistas tendemos a soslayar esta dependencia lo que, unido al desconocimiento exacto de ese marco jurídico, desvirtúa muchas veces nuestras interpretaciones y propuestas", Naredo, José Manuel (2008). "Lo público y lo privado, la planificación y el mercado, en la encrucijada actual de la gestión del agua en España". In Panel científico-técnico de seguimiento de la política de aguas, Convenio Universidad de Sevilla-Ministerio de Medio Ambiente. Disponível em: < http://www.unizar.es/fnca/varios/panel/24.pdf >, p. 1.

${ }^{33}$ En países como España, con una importante regulación de sus ríos (más de mil doscientos embalses), la simple apelación al interés general por parte de la administración para justificar la construcción, el recrecimiento de presas o los travases de cuencas - por citar tan solo algún ejemplo- está siendo severamente cuestionada desde diversos sectores sociales, hasta el punto de propugnar la necesidad de demolición de tales obras. En un movimiento que supone revertir la tendencia regeneracionista que, con base en la Ley de Obras Hidráulicas de 7 de Julio de 1911, marcó las políticas hidrológicas de la primera mitad del siglo XX español y que ha persistido en alguna medida hasta la actualidad. Esta buena fama de la que presumía la obra hidráulica en el siglo pasado, ha comenzado a ser cuestionada a partir de la necesidad de considerar la dimensión social (desplazamiento de personas e inundación de pueblos, etc.) y ambiental (inundación de bosques, alteración del ecosistema, salinización de suelos, afección de la fauna ictícola, etc.) del problema, antes soslayadas. Y en cuanto a la económica, la necesidad de evaluar global y más detenidamente la relación coste-beneficio que la obra efectivamente reporta conforme los cánones de valoración actuales.
} 
determinación de su unidad o pluralidad, su carácter trascendente o inmanente, natural o artificial, etc., para profundizar en las formas de su determinación y la potencialidad que, como concepto jurídico indeterminado, pueda tener, no sólo para la justificación del poder estatal, sino para el control del carácter discrecional que la decisión administrativa tiene en el otorgamiento, modificación y extinción de los derechos de uso especial ${ }^{34}$.

Como apunta Dworkin, el hecho de que una línea sea difícil de trazar, no significa que no haya que trazarla nuevamente o destruirla cuando ya está trazada ${ }^{35}$. Y justamente, replantear el contenido del interés público involucrado en la utilización privativa de las aguas, la forma de articulación con el interés privado y su forma de determinación y control en el contexto actual, apuntan en esa dirección.

\section{Elementos y condicionantes de la configuración actual del interés público}

\section{A) Aspectos subjetivos: titularidad y determinación de su contenido}

A pesar de estas consideraciones críticas y cuestionamientos que de manera genérica denotan ciertos problemas comunes y una incapacidad de la administración para llevar adelante en forma razonable la determinación, adecuación o readecuación del interés público implicado en las diversas situaciones concesionales, no ha dejado de ser ésta la encargada de la determinación de ese interés en el caso concreto. Dicho de otra manera, continúa siendo -al menos formalmente- el Estado -a través de sus diversos órganos- quién con mayor o menor intensidad cumple la función de mediación o intermediación para resolver la tensión que, con motivo del uso privativo de las aguas, se

\footnotetext{
${ }^{34}$ Nieto concluye, apuntando que si el poder se legitima por los intereses generales, dicha legitimación sólo opera cuando existen tales intereses y fuera de ellos la actuación se convierte en ilegítima. Así, a la vez que advierte los riesgos, pone el énfasis en la posibilidad que la conceptualización dogmática o juridificación de los intereses generales ha dado al poder judicial para proceder a su control. Nieto, A. (1997). Op. Cit., p. 2251/2252; A pesar de que Parejo Alfonso difiere de Nieto en cuanto a la posibilidad de reducir el grado de indefinición o la ulterior posibilidad de constatar la presencia de los intereses generales, no deja de poner de relieve la función de control que estos posibilitan. Así, en la segunda conclusión de su trabajo apunta: “...La definición del interés general resultante es susceptible de control jurídico desde el criterio que proporciona el orden constitucional. Pues dicha definición ha de poder ser reproducida en términos que hagan reconocible como razonable, a la luz del pertinente cuadro de valores y bienes constitucionalmente protegidos, i) la formalización de las correspondientes necesidades y fines como propias de la comunidad y a procurar o satisfacer por ésta; ii) la imputación de la procura o satisfacción a una comunidad en concreto y, además, a una precisa organización administrativa [...] Ninguna razón existe para que el rasero que proporcionan la interdicción de la arbitrariedad y la proporcionalidad quede inhabilitado cuando está en juego dicha noción". Parejo Alfonso, L. (2005). Op. Cit., p. 268.

${ }^{35}$ Dworkin, Ronald (1996). "La discrimination positive". In Une question de principe, Paris: Puf, p. 378.
} 
genera en forma permanente entre lo particular y lo general, entre interés privado e interés público

Y ello por cuanto, si bien es posible constatar el surgimiento de instituciones o sectores con pretensiones de reemplazar al Estado o alguna de sus funciones ${ }^{36}$, a partir de una supuesta mejor o más fidedigna representación de los intereses generales fenómeno que no resulta por otra parte en medida alguna novedoso-, ellas no han sido capaces hasta el momento de justificarlo suficientemente en el plano teórico, ni de alcanzar grados de efectividad y legitimidad que en la práctica permitan operar el reemplazo del aparato estatal. Sí en cambio, como veremos adelante, tal fenómeno ha encontrado eco y curso en reformas legislativas que procuran posibilitar una mayor participación de tales sectores -no representados en la tradicional participación a través de los organismos de usuarios-, en la determinación de ese contenido ${ }^{37}$.

Desde una perspectiva, puede decirse que los mercados y bancos de aguas "sustituyen" la determinación estatal de ese interés público en el caso concreto por una decisión del "mercado" que actúa en el marco de una pseudocompetencia regida por leyes de oferta y demanda, posibilitando reasignaciones al margen de la decisión estatal. Pero su nula o escasa implementación en Argentina, sumada a la ineficacia y el mantenimiento de la intervención estatal en los pocos casos en que efectivamente tales mecanismos han sido contemplados ${ }^{38}$, debe llevar a concluir que tampoco por esta vía se

\footnotetext{
${ }^{36}$ Nos referimos al denominado tercer sector ONG's, Organizaciones de la Sociedad Civil, etc., cuya aspiración última reside muchas veces propiamente en el reemplazo de las funciones estatales.

37 Así por ejemplo, y prescindiendo de la consideración general de los instrumentos participativos incorporados por la reforma de constitucional del 1994, se prevé la incorporación de procesos de participación entre todos los involucrados y actores interesados para la fijación y actualización de usos prioritarios, límites de vertido y estándares de calidad de los cursos de agua (arts. 12/47 LGAA de CABA de 2010). En relación específica a las cuestiones ambientales la LGA № 25675 (2002) ha regulado con carácter de PMPA el derecho a la participación disponiendo que "Toda persona tiene derecho a ser consultada* y a opinar en procedimientos administrativos que se relacionen con la preservación y protección del ambiente, que sean de incidencia general o particular, y de alance general" (art. 19); "Las autoridades deberán institucionalizar procedimientos de consultas o audiencias públicas como instancias obligatorias para la autorización de aquellas actividades que puedan generar efectos negativos y significativos sobre el ambiente. La opinión u objeción de los participantes no será vinculante para las autoridades convocantes; pero en caso de que éstas presenten opinión contraria a los resultados alcanzados en la audiencia o consulta pública deberán fundamentarla y hacerla pública"(art. 20); "La participación ciudadana deberá asegurarse, principalmente, en los procedimientos de evaluación de impacto ambiental y en los planes y programas de ordenamiento ambiental del territorio, en particular, en las etapas de planificación y evaluación de resultados"(art. 21). En estrecha vinculación con el derecho a la participación, también la legislación nacional ha regulado con carácter de PMPA el derecho a la información por Ley № 25831 (2004) sobre libre acceso a la información pública ambiental. "Vale aclarar que el "a ser consultada" fue observado por el PEN en su promulgación.

${ }^{38}$ La experiencia del derecho chileno comparado que ha debido morigerar (Ley 20017 de 2005) el carácter fuertemente liberal de su legislación (CAg. de Chile de 1981), enseña también que la prescindencia del
} 
ha afectado el monopolio en la determinación estatal de la definición del interés público involucrado en la utilización de agua pública ${ }^{39}$.

Tal postulado inicial no importa la reafirmación lineal del dogma decimonónico, ya superado en bastante medida, que concebía a la administración pública de manera abstracta, como representante auténtica de los intereses generales, sin ningún tipo de matización y con prescindencia de todo tipo de participación y control. Y ello refiere, tanto en el contenido -plano sustancial-, como en el procedimiento para la toma de la decisión estatal en la que se opera la concreción de ese interés público o general en relación a la utilización privativa de las aguas.

La superación de esa concepción decimonónica de la Administración y el Estado teorizada en forma ciertamente incompleta junto con la crisis de la democracia indirecta representativa pura que le servía de base, encuentran su respuesta en la recepción constitucional y legal de diversos mecanismos de participación de los que no puede prescindirse en la actualidad para la definición del interés público concreto que sin embargo sigue, aunque de manera diversa, en cabeza de la administración.

Ello invita a replantear algunas de las modalidades que han caracterizado los derecho de uso especial hasta la actualidad, como la falta de procedimientos que garanticen el principio de igualdad, la falta de un precio por el agua, la perpetuidad de los derechos, la ya referida prescripción como modo de adquisición y la excesiva discrecionalidad e ineficacia de la administración en las diversas fases por las que atraviesa la vida de los derechos, entre otros.

No sólo porque quizás halle suficientes fundamentos la diferenciación actual entre los intereses generales y los del Estado propiamente, y la consecuente e inacabada representación del interés general que la administración lleva adelante respecto de los intereses de los ciudadanos en situaciones concretas ${ }^{40}$. Sino porque la identificación,

Estado en esa determinación acarrea para el interés público o general demasiados riesgos y problemas en relación a los beneficios particulares que reporta.

${ }^{39}$ Bajo la denominación de estatal, se incluye las instancias supra estatales que adquieren protagonismo en la definición de los intereses públicos en los en el marco de los procesos de integración actuales.

${ }_{40}$ Salomoni ha señalado que la calificación constitucional de los derechos de los usuarios (art. $42 \mathrm{CN}$ ) pone en tela de juicio uno de los postulados sobre los que se asienta nuestro sistema de derecho administrativo cual es el de considerar a la administración Pública vicaria de los intereses generales, Salomoni, J. L. (1999). Teoría general de los servicios públicos, Buenos Aires: Ad Hoc, p.179. A su turno Gordillo afirma que el interés público no es el interés de la Administración pública y ejemplifica: "...El juego es decididamente contrario al interés público, y sin embargo, explotado por la Administración (hipódromos, loterías, etc.) redunda claramente en beneficio de ésta; el poder detener a las personas, "demorarlas", e inclusive torturarlas a fin de obtener una confesión, coincide con el interés de las fuerzas de seguridad de aprehender a los posibles delincuentes, pero colinde con el interés público de que haya un cierto grado de respeto a la persona humana; si una empresa ofrece prestar ingentes capitales al Estado a cambio de una 
definición y composición de ese "interés general", distinto del de la administración, es lo que se ha modificado. Es a partir de esta distinción que notamos, que se hace necesario encontrar criterios y puntos de referencia que permitan efectuarla debidamente y llevarla a la práctica en el campo de la utilización privativa de las aguas.

\section{B) Aspectos objetivos sustanciales}

Las leyes liberales decimonónicas de agua cumplieron la finalidad de brindar seguridad a los concesionarios y proceder a la ordenación administrativa de los distintos aprovechamientos para garantizar el orden público y la paz social en el marco de un paradigma que privilegió el uso económico de los recursos. En ese contexto, como ya se notó, es evidente que el uso ideológico del concepto de interés público destinado preponderantemente a legitimar el actuar estatal contemplado en las concesiones reconocidas y otorgadas a fines del siglo XIX y principios del $X X$, no puede seguir vigente en idénticos términos en la actualidad ${ }^{41}$. Y ello por cuanto, aunque ciertamente obvio, merece la pena recalcarlo, la noción de interés público es esencialmente contingente, resultando imposible -al decir de Hariou- formular una definición válida para todos los tiempos y para todos los países, puesto que se encuentra en gran parte bajo la dependencia de las costumbres y transformaciones sociales ${ }^{42}$.

El nuevo contenido y la reconfiguración de ese interés público, debe hacerse a partir de la integración de las transformaciones acaecidas en la base del derecho de aguas. La sola consideración de la dimensión ambiental del agua (art. 41 CN; Ley 25.688 de gestión ambiental de las aguas) ha hecho tambalear el contenido de la concepción decimonónica del interés público implicada en muchas concesiones, como se evidencia por ejemplo, en la conflictividad entre usos consuntivos y caudales ecológicos. De allí, la importancia central que los mecanismos de modificación, revisión y extinción concesional adquieren en la readecuación del contenido del interés público a las necesidades actuales. O la reconsideración de la dimensión social de ese interés público, en relación con un hecho muy concreto, como es la consagración de la ineludible responsabilidad

concesión de servicios públicos, el interés de la Administración es favorable al pacto, por cuanto obtiene capitales baratos y hace prestar el servicio: mas el interés público es que el servicio público sea prestado por quien tiene más aptitud para hacerlo con eficiencia, no por quien está en condiciones de hacerle algún favor a la Administración.", Gordillo, A. (2004). Op. Cit., p. 10.

${ }^{41}$ Martin-Retortillo, S. (1997). Derecho de Aguas, Madrid: Civitas, p. 278.

${ }^{42}$ Hariou, Maurice (1929). Précis de Droit Constitutionel, Paris: Recuil Sirey, p. 99. 
estatal por la satisfacción progresiva de un derecho humano al agua (art. 75 inc. 22 CN). Todos aspectos de los que resulta un ejemplo acabado la LGAAg. CABA de 2010 que privilegia la dimensión ambiental en el uso del agua con necesaria participación de los ciudadanos (arts. 10/12), a la vez que prevé un régimen permisional flexible y adaptable con exiguos plazos (arts. 27 a 37), garantizando el derecho humano al agua a todos los habitantes (art. 3).

La necesidad de precisar el contenido del interés público, en relación a un contexto jurídico-político determinado, ha sido puesta de relieve por Martín-Retortillo desde otro punto de vista al puntualizar que no cabe considerar las distintas fórmulas -permiso, concesión, etc.- como esquemas meramente abstractos 0 formales, ya que necesariamente se hallan mediatizadas y penetradas por las opciones de política hidráulica, que reflejan en definitiva los condicionamientos que los cometidos del poder imponen a la utilización de los recursos. Así, concluye advirtiendo que, escindir las fórmulas habidas para la utilización del recurso hídrico del precitado contexto equivale a reducirlas a la pura abstracción, negándoles toda operatividad ${ }^{43}$.

Lo antedicho permite afirmar que la determinación del contenido del interés público no es libre para la administración, sino que su discrecionalidad está mediatizada o penetrada -en palabras de Martin-Retortillo- no sólo por las opciones políticas, sino también por las diversas limitaciones provenientes del contexto jurídico que se conectan con los planos de análisis cuya consideración simultánea propusimos al comienzo.

Desde el punto de vista político, entonces, si bien el Estado mantiene el monopolio en su determinación, los niveles de discrecionalidad son relativos, puesto que tal actividad de definición debe ser llevada a cabo en el marco de una planificación hidrológica con participación necesaria de diferentes sujetos. La determinación estatal exclusiva 0 articulada a partir de la tradicional y preponderante participación acordada a los usuarios -titulares de derechos de aprovechamiento al uso privativo de las aguas públicas- ${ }^{44}$, se extiende ahora también a los ciudadanos cuyos intereses aparecen representados en

\footnotetext{
${ }^{43}$ Martin-Retortillo, S. (1997). Op. Cit., p. 201.

${ }^{44}$ No todas, pero buena parte de las provincias Argentinas tienen incorporado en su legislación positiva de aguas el principio de participación de los usuarios en la administración y gestión del agua (Mendoza, Salta, Córdoba, Buenos Aires y Tucumán, entre otras). Mendoza en particular, cuenta con una larga tradición que reforzada por la influencia de la legislación española se remonta a tiempos anteriores a la conquista ha determinado la jerarquía constitucional del principio de participación de los usuarios en los siguientes términos. "Las Leyes sobre irrigación que dicte la Legislatura, en ningún caso privarán a los interesados de los canales, hijuelas y desagües, de la facultad de elegir sus autoridades y administrar sus respectivas rentas, sin perjuicio del control de las autoridades superiores de irrigación." (art. 187 CP de Mendoza). Consagración de un principio formulado en el contexto decimonónico cuya resignificación es también preciso efectuar en la línea de las transformaciones que venimos desarrollando.
} 
distintas instancias (administrativas, legislativas, judiciales, en la etapa de formación o ratificación de la voluntad y de control, entre otras) de diversas maneras, sea individual o colectivamente, a través asociaciones o en virtud de la representación ejercida por órganos estatales y no estatales especialmente predispuestos al efecto ${ }^{45}$.

Esto es lo que refleja la última legislación en materia de aguas al preveer la obligación de implementar procesos de participación entre todos los involucrados y actores interesados para la fijación y actualización de usos prioritarios, límites de vertido y estándares de calidad de los cursos de agua (arts. 12/47 LGAAg de CABA de 2010). Todo ello de acuerdo con la profundización de los sistemas democráticos que, a través de diversos mecanismos de participación, busca superar la profunda crisis de representación y legitimidad del Estado de derecho actual.

Su carácter discrecional, no sólo no puede implicar arbitrariedad sino que, va de suyo, nunca puede ser considerado absoluto en tanto siempre debe ser ejercida conforme a normas. Es decir, en tanto la actividad de la administración está siempre sujeta a reglas o normas, con lo cual sólo es posible hablar de grados de discrecionalidad en el sentido antes explicado. Como apunta Gordillo todo acto es en parte reglado y en parte discrecional ${ }^{46}$. Discrecionalidad que encuentra su límite en el ordenamiento jurídico, pero también en el plano fáctico al cual va dirigida la determinación.

Lo que aquí interesa, principalmente, es que tal determinación política del contenido del interés público se encuentra subordinada sin embargo a principios jurídicos concretos. En el plano sustancial, las transformaciones constitucionales (1994) y legales de los últimos años suponen que ese interés, que atendía hasta el momento principalmente la dimensión económica, deberá enderezarse a una consideración equilibrada de las dimensiones ambiental y social, tal como se desprende en Argentina de la inteligencia efectuada en la primera parte sobre la inclusión de los artículos 41, y 75 inc. 19,22 y $23 \mathrm{CN}$.

Esto es lo que han sostenido autores españoles sobre la base de la jurisprudencia del Tribunal Constitucional al reconocer que:

\footnotetext{
${ }^{45}$ En Argentina, a más de las ONGs (Organizaciones No Gubernamentales) u OSCs (Organizaciones de la Sociedad Civil), encuadrables desde el punto de vista jurídico entre las asociaciones civiles sin fines de lucro, han desarrollado un rol bastante activo en defensa de los intereses de los ciudadanos el Defensor del Pueblo de la Nación -de raigambre constitucional (art. 86 CN)- y los ombusman o defensores del pueblo instituidos a nivel provincial y municipal.

${ }_{46}$ Gordillo, A. (2009). Tratado de Derecho Administrativo, 10. ed., Buenos Aires: Fundación Derecho Administrativo, T. 1, p. X-22 y ss.
} 
[...] La titularidad estatal sobre el dominio público marítimo-terrestre no es, pues, una mera forma vacía de contenido o susceptible de acoger cualesquiera determinaciones establecidas por el legislador, sino que comporta mandatos positivos a éste, al menos en la triple dirección que indica el propio Tribunal: defensa de la integridad, garantía de uso público y preservación de los valores paisajísticos ${ }^{47}$.

La jurisprudencia del Tribunal Supremo español ha sido también elocuente al ponderar los elementos del nuevo contenido del interés público. Por ejemplo, al decidir el rechazo de un recurso que solicitaba la suspensión del acto administrativo que ordenaba la instalación de un módulo de caudal, argumentando que la defensa de las aguas de dominio público y su uso racional constituyen un contenido permanente del interés público $^{48}$.

\section{C) Aspectos objetivos procedimentales}

Desde el punto de vista procedimental, su determinación se materializa en la planificación hidrológica fundamentalmente. Pero abandona su carácter de decisión centralizada autoritaria en las diversas instancias del procedimiento concesional (otorgamiento, revisión, revocación). Encontrándose, ahora y cada vez más, sometida a una mayor participación en la conformación de su contenido (sea directa en órganos directivos y/o consultivos, o a través de mecanismos indirectos como el referéndum, audiencias públicas, documentos de consulta, etc. $)^{49}$, un deber de información y a una reducción del grado de discrecionalidad, producto de una mayor reglamentación y un control judicial más amplio ${ }^{50}$.

En este sentido, se ha puesto de relieve el carácter reestructurante que el principio de participación [arts. 19-21 LGA (Ley General del Ambiente) 25675; Ley 25831 de Información Pública Ambiental] tiene respecto del régimen de información y su contribución a la democratización de las decisiones ${ }^{51}$. Así lo ha reconocido Embid Irujo al

\footnotetext{
${ }^{47}$ Menendez Rexach, Ángel (2004). "El dominio público como...”. In Revista jurídica Universidad Autónoma de Madrid, n. 10, p. 222.

${ }^{48}$ STS (Sentencia del Tribunal Supremo) de 26 de noviembre de 2002 (Ar. 10387).

${ }^{49}$ Vid. arts. $10 / 12$ y 47 de la LGAA de CABA de 2010.

50 La reforma constitucional de 1994 (arts. $41 / 42 / 43 \mathrm{CN}$ ) ha posibilitado una expansión considerable del control judicial sobre la actividad administrativa. Básicamente a partir del reconocimiento constitucional y generalización del procedimiento de amparo y la formidable ampliación de la legitimación procesal de distintos sujetos para accionar en defensa de intereses individuales, colectivos y difusos (art. $43 \mathrm{CN}$ ).

${ }^{51}$ Con referencia a la LGA 25675 se ha sostenido que "...La ley -25675- establece como objetivos el de fomentar la participación social en los procesos de toma de decisión, y confiere acciones a los particulares para la búsqueda de información, y para la prevención en materia de decisiones con impacto ambiental [...] se democratiza la toma de decisiones, de modo que todos opinen, generando una solución consensuada. El
} 
señalar que la fundamentación de la normativa de la participación es que se incorporen al conocimiento de la política del agua, visiones sectoriales no han sido hasta el momento tenidas en cuenta dado que la administración necesita a todas ellas para formar su política y, sobre todo, dadas las características del gobierno de una sociedad moderna y del conocimiento, para buscar la mayor legitimación posible de tales políticas ${ }^{52}$.

De hecho, uno de los desafíos más grandes que plantea la actualidad, en orden a la determinación de tal interés, es aquel relativo a la armonización del respeto de los derechos adquiridos al uso especial del agua con las crecientes necesidades de reglamentación e intervención que requiere el Estado, y la sociedad, para su readecuación a las demandas actuales. Toda vez que por un lado, debe considerarse la forma invariable en que tales derechos han sido considerados amparados por la garantía constitucional de la propiedad privada (art. $17 \mathrm{CN}$ ), cuestión que involucra desde luego la discusión sobre su naturaleza jurídica, la función social de la propiedad (arts. 14, 17 y 28 $\mathrm{CN}$ ), etc.; y por otro, el incremento de la intensidad de las potestades de regulación sobre las aguas públicas desde el punto de vista ambiental (arts. 41, 124, $121 \mathrm{CN}$, entre otros) y social (art. 75 inc. 19/22/23 CN) que permite evidenciar particularidades respecto de la reglamentación sobre otro tipo de bienes ${ }^{53}$.

Con todo, hay que decir que si bien no parece posible desde el punto de vista conceptual definir al interés público en abstracto, sí lo es la constatación del desempeño de diversas funciones centrales que el mismo cumple en el sistema jurídico político del uso especial del agua pública. En tal sentido, es dable proceder a su identificación junto con las notas que en la actualidad contribuyen desde el punto de vista sustancial a perfilar

dialogo social jurídicamente descentralizado reemplaza a la decisión autoritaria centralizada. Es muy relevante a estos fines concebir la información de otra manera, ya que para el diálogo y las decisiones se precisa de información...", Lorenzetti, R. (2003). "La nueva ley ambiental argentina”, LL, 2003-C, 1332. In Responsabilidad Civil, Doctrinas Esenciales, Tomo V, p. 1541. La DMA 2000/60/CE (Directiva Marco del Agua) reconoce en el preámbulo que su éxito depende de una colaboración estrecha y una actuación coherente de la Comunidad, los Estados miembros y las autoridades locales, así como de la información, las consultas y la participación del público, incluidos los usuarios. (pto. 14 DMA). En particular, reconoce un rol muy preponderante a la participación, estableciendo un procedimiento de información, consulta pública y notificación obligatorio que manda a los Estados miembros a fomentar.

52 Embid Irujo, A. (2008). Op. Cit., p. 63.

${ }^{53}$ La crisis del agua y los nuevos requerimientos ambientales que motivan su creciente regulación por parte de los poderes públicos (el posible incremento del "precio", la limitación de caudales, la prohibición de utilización de agroquímicos, la exigencia de tecnología, de depuración de las aguas y de requisitos para su vertido) importa en algunos casos una sustancial modificación del título concesional que puede afectar el patrimonio que tales derechos comportan en cabeza de su titular. Podría afirmarse que se trata de nuevos límites o restricciones legítimas impuestas en ejercicio de la potestad regulatoria sobre la utilización de los bienes del dominio público hidráulico, en su caso, de una manifestación del poder policial del Estado (aplicables tanto a aguas públicas como privadas), o podría también alegarse que se trata de modificaciones unilaterales del título concesional, verdaderas desnaturalizaciones del derecho de propiedad que debieran conllevar algún tipo de reparación. 
el contenido posible del concepto jurídico-político. Notas cuya contingencia o validez temporal resulta indudable a la luz de las consideraciones expuestas.

Ahora bien, el reconocimiento del indudable carácter funcional y esencialmente dinámico de la noción, lleva también a poner en el centro de la atención el mecanismo a través del cual es determinado o identificado, no en el plano semántico o discursivo, sino en el específico campo del derecho donde se le atribuyen concretas consecuencias jurídicas.

En tal supuesto, y haciendo eco de esa pluralidad o heterogeneidad de intereses públicos que la doctrina ha reconocido de entre los intereses del conjunto social, sólo a algunos, los identificados por la administración o el Estado en un momento determinado sea a través de actos administrativos o, en su caso, por la ley o la jurisprudencia-, conforme el contenido sustancial circunstancial dado por las normas y el procedimiento establecido -en el cual la participación ha adquirido un rol preponderante-, es posible atribuirles consecuencias jurídicas.

En efecto, en la actualidad es posible constatar que, en la definición de ese interés, la administración ha dejado de tener la libertad y discrecionalidad que caracterizó el otorgamiento de las concesiones en el contexto decimonónico, debiendo estar sujeta -al menos en teoría- a los distintos tipos de procedimientos y controles, democráticos y judiciales antes referidos.

\section{Conclusiones}

Con base en lo expuesto puede concluirse que:

a) La relación interés público (y privado) es la lógica que articula y justifica desde el punto de vista teórico el uso especial de las aguas del dominio público. Esta relación dialéctica se evidencia con toda claridad en el otorgamiento, modificación y extinción de los derechos de agua y se proyecta sobre todo su régimen jurídico. Entre ambos tipos de interés no existe una contraposición ni identificación absoluta sino una relación dialéctica dinámica, que varía conforme cambian las circunstancias de tiempo y lugar, pudiendo implicar identidad, negación o llegado el caso, una sumatoria de los mismos. No es posible concebir un interés general abstracto e indeterminado sino intereses públicos concretos, plurales y heterogéneos. 
b) Muchas de las dificultades teóricas y disfuncionalidades constatadas en el régimen jurídico de los derechos aguas (perpetuidad, irrevocabilidad, prescripción, ausencia de igualdad y concurrencia, etc.), pueden ser explicadas desde el congelamiento del contenido de la relación interés público-interés privado y el mantenimiento acrítico de la sistematización que le dio sustento. O lo que es igual, en la falta de reconocimiento por parte del los operadores del derecho de la variación de las circunstancias objetivas normativas y fácticas. Tales disfunciones, reflejan parte de la crisis del dogma liberal decimonónico en el marco del cual resultó posible que la administración definiera, sin condicionamientos ni controles, qué intereses privados pasaban a ser públicos, dejando traslucir un concepto de interés público que adquiría connotaciones permanentes o definitivas, cuando no desempeñaba una función claramente ideológica.

c) La precisión del marco jurídico constitucional puede interpretarse como una reducción del nivel de indeterminación del interés público implicado en el uso especial de las aguas públicas. Aunque el Estado mantiene el monopolio de su determinación en el caso concreto, ha dejado de ser considerado su titular exclusivo. En el plano sustancial su contenido aparece fuertemente condicionado por el principio de uso racional y sustentable (obligación de uso, ahorro y eficiencia, prohibición de contaminar, preservación de la fuente, etc.) (art. $41 \mathrm{CN}$ ) y la realización del derecho humano al agua (arts. 75 inc. 19 y 22/23 CN) que integran a la económica el contenido ambiental y social. En lo procedimental, aparece determinado por la planificación hidrológica, la ampliación de la participación, el derecho a la información, los principios de igualdad y libre concurrencia, la reducción de la discrecionalidad y la ampliación del control judicial suficiente.

\section{Referências}

AAVV (2005). Lo público y lo privado en la gestión del agua. Experiencias y reflexiones para el siglo XXI, Madrid: Ediciones del oriente y del mediterráneo.

Alberdi, Juan Bautista (1998). Fragmento Preliminar al estudio del Derecho (1837), Buenos Aires: Ciudad Argentina.

Beltrán de Felipe, M. (1995). Discrecionalidad administrativa y Constitución, Madrid: Tecnos.

Bullinger, Martin (1976). Derecho público y Derecho privado, Madrid: Instituto de Estudios Administrativos. Traducción A. Esteban Drake. 
Cassese, Sabino (2003). La crisis del Estado, Buenos Aires: Abeledo Perrot.

Comadira, Julio R. (2004). "El Derecho Administrativo como régimen exorbitante en el servicio público". In Servicio Público, Policía y Fomento, Jornadas organizadas por la Universidad Austral Facultad de Derecho, RAP.

D’Argenio, Inés (2007). "La ideología estatal del interés general en el derecho administrativo". In RDA, Buenos Aires, n. 59.

De Cabo de la Vega, A. (1997). Lo público como supuesto constitucional, México DF: UNAM.

Dworkin, Ronald (1996). Une question de principe, Paris: Puf.

Embid Irujo, Antonio (1997). "Público y privado en la construcción, explotación y mantenimiento de obras hidráulicas". In Revista de la Administración Pública, n. 143, p. 29-75.

(1998). "La evolución del derecho de aguas y las características de la actual problemática del agua". In Emrid Irujo, A. (Dir.) (1998). El nuevo derecho de aguas: Las obras hidráulicas y su financiación, Madrid: Civitas.

(2008). "Usuarios y ciudadanos: participación e información en el derecho español de aguas. Historia, presente y futuro". In Embid Irujo, A. (Dir.) (2008). Ciudadanos y Usuarios en la gestión del agua, Aranzadi: Cizur Menor.

Escola, H. J. (1989). El interés público como fundamento del derecho administrativo, Buenos Aires: Depalma.

Garces, Ángel (1999). "Aspectos prácticos de la planificación y de gestión institucional del agua. La gestión privada de intereses públicos". In AAVV (1999). El Agua a Debate en la Universidad. Hacia una nueva cultura del agua, Zaragoza, p. 775-782.

(2001). "Participación Social y gestión institucional del agua". In Una cita europea con la nueva cultura del agua: La directiva marco. Perspectivas en Portugal y España, Zaragoza, p. 463-480.

(2005). “El interés general como aspecto esencial del dominio hidráulico”. In Revista Aragonesa de Administración Pública, n. 27, p. 137-150.

García de Enterría, E. (1996). Democracia, jueces y control de la Administración, 2. ed., Madrid: Civitas.

Giannini, Massimo Severo (1970). Diritto Administrativo, Milano: Giuffrè, v. I.

Gordillo, A. (2004). "Reestructuración del concepto y el régimen jurídico de los servicios públicos", Buenos Aires. In Paginas de Ayer 2004 - 10, 29, LL. 
(2009). Tratado de Derecho Administrativo, 10. ed., Buenos Aires: Fundación Derecho Administrativo, T. 1.

Habermas, Jürgen (1981). Historia crítica de la opinión pública, Barcelona: G. Galli.

Hariou, Maurice (1929). Précis de Droit Constitutionel, Paris: Recuil Sirey.

Hegel, G.W.F. (1975). Principios de la filosofía del derecho o derecho natural y ciencia política, Bs. As.: Sudamericana.

Hernández Martínez, Ma. del Pilar (1997). Mecanismos de tutela de los intereses difusos y colectivos, México: Instituto de Investigaciones Jurídicas, UNAM.

Kelsen, Hans (1995). ¿Quién debe ser el defensor de la Constitución?, Madrid: Tecnos.

Lorenzetti (2003). "La nueva ley ambiental argentina", LL, 2003-C, 1332. In Responsabilidad Civil, Doctrinas Esenciales, Tomo V.

Marienhoff, M. (1960). Tratado del Dominio Público, Buenos Aires: TEA.

(1996). Régimen y legislación de las aguas públicas y privadas, 3. ed., Buenos Aires: Abeledo Perrot.

Martin, Liber et al (2010). El derecho humano al agua. Particularidades de su reconocimiento, evolución y ejercicio, 2. ed. actual., Buenos Aires: Abeledo Perrot.

Martin-Retortillo, S. (1997). Derecho de Aguas, Madrid: Civitas.

Menendez Rexazh, Ángel (2004). "El dominio público como institución jurídica: configuración histórica y significado actual en el derecho público español". In Revista jurídica Universidad Autónoma de Madrid, n.10, p. 209-226.

Naredo, José Manuel (2008). "Lo público y lo privado, la planificación y el mercado, en la encrucijada actual de la gestión del agua en España". In Panel científico-técnico de seguimiento de la política de aguas, Convenio Universidad de Sevilla-Ministerio de Medio Ambiente. Disponivel em: <http://www.unizar.es/fnca/varios/panel/24.pdf>.

Nieto, A. (1997). "La Administración sirve con objetividad a los intereses generales". In Estudios sobre la Constitución Española (Homenaje a Eduardo García de Enterría), Madrid: Civitas, v. III, p. 2185-2254.

Parejo Alfonso, Luciano (2005). "Interés público como criterio de control de la actividad administrativa". In AAVV, Constitución, Estado de las Autonomías y Justicia Constitucional, (Homenaje a Grumersindo Trujillo), Valencia: Tirant lo Blanch, p. 251-270.

(2007). "Estudio preliminar". In Marin Hernandez, Hugo A. (2007). Discrecionalidad Administrativa, Bogotá: Universidad Externado de Colombia, p. 38-39.

Rangeon, Francois (1986). L’idéologie de l'íntéret general, Paris: Económica. 
Sainz Moreno, F. (1976), Conceptos jurídicos, interpretación y discrecionalidad administrativa, Madrid: Civitas.

Salomoni, J. L. (1999). Teoría general de los servicios públicos, Buenos Aires: Ad Hoc. (2002). "Interés Público y Emergencia". In Revista Actualidad en el Derecho Público, Buenos Aires, n. 18-20.

(2006). Ordenamientos Internacionales y Ordenamientos Administrativos Nacionales. Jerarquía, impacto y derechos humanos, Buenos Aires: Ad Hoc.

Sanchez Moron, M. (1980). La participación del ciudadano en la Administración pública, Madrid: Centro de Estudios Constitucionales.

Weber, Max (1969). Economía y sociedad, México: FCE, T. II.

Recebido para publicação em novembro de 2012.

Aprovado para publicação em dezembro de 2012. 